Mini Review

\title{
Human embryonic stem cells: A model for human ageing in vitro
}

\author{
S.H. Cedar ${ }^{\mathrm{b}}$, S.L. Minger ${ }^{\mathrm{a}, *}$ \\ ${ }^{a}$ Stem Cell Biology Laboratory, Wolfson Centre for Age Related Diseases, King's College, London SE1 1UL, United Kingdom \\ ${ }^{\mathrm{b}}$ Experimental Ageing Research Laboratory, FHSC, London South Bank University, London SE1 OAA, United Kingdom
}

\section{A R T I C L E I N F O}

\section{Article history:}

Received 16 April 2008

Received in revised form 26 June 2008

Accepted 30 June 2008

Available online $\mathrm{xxxx}$

\begin{abstract}
A B S T R A C T
Stem cells have been used to investigate developmental processes and may be used as a therapeutic source of material for regenerative medicine and cancer. Here we propose the use of human embryonic stem cells, which represent a youthful phenotype, as models for experimentally investigating human ageing.
\end{abstract}

(c) 2008 Elsevier Inc. All rights reserved.

\section{Keywords:}

Human embryonic stem cells

Somatic cells

Germ cells

Pluripotency

Induced pluripotent stem cells

Ageing

Self-renewal

Senescence

\section{Stem cells}

All the cells of the human body are originally derived from the fertilised egg cell. This cell multiplies by division and the progeny cells differentiate to form all the somatic and germ cells of the body. Human embryonic stem cells (ESC) were first isolated in 1998 (Thomson et al., 1998). Worldwide there are now a number of laboratories growing human ESC lines. Human ESC are characterised by their ability to form all the germ layers of the embryo and therefore are called pluripotent, in contrast to somatic stem cells (SSC) found in the various compartments of the body which are thought to be restricted to forming cells within their particular compartment and are thus termed multipotent. Both types of stem cell, ESC and SSC, are able to replicate themselves (self-renew). Somatic stem cells undergo replicative senescence in vitro, but ESC are though to be able to self-renew indefinitely as well as maintaining pluripotency (Amit et al., 2000). These two characteristics, potency to form many cell types and self-renewal, have made ESC of interest in various fields of biology and medicine, for example in regenerative medicine looking to replace degenerated tissues in diseases such as Myocardial Infarction, Alzheimer's and Parkinson's, and in cancer, as cancer may be caused by mutations in stem cells.

\footnotetext{
* Corresponding author. Tel.: +44 2078154705.

E-mail address: cedars@lsbu.ac.uk (S.L. Minger).
}

Currently, models of ageing are either of animals that may not reflect human ageing or of degenerative diseases or differentiated cells, where the ageing process, such as senescence, has already commenced. This paper proposes that ESC may also be of great use in ageing research providing a source of material on which to test mechanisms of ageing.

\section{Isolation of human ESC}

In humans embryos can be created during in vitro fertilisation (IVF). These IVF embryos can be implanted and give rise to offspring as seen by the first IVF birth of Louise Brown (Steptoe and Edwards, 1978). Surplus embryos can be donated for laboratory research. Human ESC are isolated from the Inner Cell Mass of the day 5-6 blastocyst. The blastocyst is a collection of cells derived from the fertilised egg. The cells of the blastocyst divide and differentiate to form an outer layer referred to as trophectoderm, which will form the placenta, a feature of mammalian development and the inner cell mass (ICM) that will form all the somatic cells and the germ cells of the embryo. The somatic cells form all the cells of the body, soma, while the germ cells will form the future generation. ESC cells are derived from the ICM. These ESC cells can form all the somatic cells of the body found in what are referred to as three germ layers of the developing embryo, the endoderm, mesoderm and ectoderm.

From current data, embryonic cells are reset as 'youthful' regardless of the age of the donors from which they are derived 
(Carlson and Conboy, 2007). The cell lines so far established show pluripotency and the ability to continuously divide in culture. These two characteristics, self-renewal and pluripotency may act independently of each other. Mouse ESC in long-term culture showing loss of some pluripotency while maintaining self-renewal (Li et al., 2007).

Here, we propose a new line of research in ageing where these human ESC lines can provide a model for human ageing allowing various environmental factors or genetic manipulation to be tested to see the effects on potency and replication. In this way ESC may offer a way of modelling and dissecting human ageing. The use of these ESC lines for ageing research depends on many biological markers discussed below.

\section{Ageing and biomarkers}

One of the problems for ageing research is defining ageing. Lifespan, which is generally thought to be increasing in many human populations, is a measure of longevity; ageing is synonymous with health. Biomarkers of ageing often measure the results of ageing rather than the underlying processes.

Biomarkers need to predict ageing events and ageing may not necessarily be a degenerative process, merely a developmental one. Currently, telomeres and telomerase appear to be biomarkers that not only measure longevity, but may predict the processes of cellular ageing, senescence. Cell division is found in the early, 'undifferentiated' cells whose only function is to provide cells for the developed compartment that carry out all the functions of the body. However, the cessation of cellular division is the norm in the somatic cells which carry out the physiological functions of the body, even in the 'youthful' body. The terminally differentiated, functional cells are supplied by earlier progeny cells that are themselves provided by Somatic Stem Cells, SSC, found in most compartments of the foetal and adult body and restricted to providing progeny in that compartment, i.e. multipotential, rather than pluripotential as in the ESC.

Nevertheless, cellular senescence, the loss of ability of cells to divide, is thought to be both a sign of and a cause of ageing in cells. ESC appear to be able to divide ad infinitum (Carpenter et al., 2004).

\section{Self-renewal}

The ability of cells to divide depends on a number of factors including cell cycle control proteins, telomeres and telomerase and DNA repair.

\subsection{Cell cycle}

One of the characteristics of stem cells is their ability to divide to provide cells for development into functional, mortal differentiated cells. To produce new cells DNA synthesis must occur. The cell cycle is under strict homeostatic control to match cell division to cell loss. Cyclins and cyclin-dependent kinases (Cdks) are the major proteins controlling the cell cycle by phosphorylation of target genes (Morgan, 1995). Some of the target genes include p53 and $\mathrm{Rb} 2$ tumour suppressors. Both of these prevent the cell progressing through the cell cycle after damage to the DNA allowing repair or apoptosis to occur. In contrast to mouse ESC analysis of human ESC by massive parallel sequencing analysis showed that p53 and genes such as p16, p19 and p21 that cooperate with p53 are not expressed or are expressed at very low levels. (Brandenberger et al., 2004), indicating that the absence of the p53 pathway is required for human ESC to bypass senescence. Rb and the transcription factor E2F to which $\mathrm{Rb}$ binds to prevent cells entering $\mathrm{S}$ phase (Wein- berg, 1995) and are absent in ESC (Miurra et al., 2004) which may be the cue to allow ESC to self-renew.

\subsection{Telomeres and telomerase in ESC}

Telomeres are found at the termini of eukaryotic chromosomes. They consist of long tandem repeats of TTAGGG sequence and function to protect chromosomes from fusion and loss of genetic material, especially during synthesis and division of DNA (Bodner et al., 1998). They are maintained by an enzyme, telomerase, a ribonucleoprotein comprising various subunits such as Tert and Tep1. It is thought that telomeres shorten during each cell division and that telomerase activity declines during development. Initial results suggest that telomere lengths and telomerase are maintained in ESC (Carpenter et al., 2004). While ESC maintain their telomerase activity, unlike cancer cells and many cells grown in vitro, they also maintain a normal karyotype (Carpenter et al., 2004).

\subsection{DNA repair}

During normal metabolism and cell division DNA is susceptible to damage. Environmental insults, such as UV irradiation and oxidative stress add an extra burden to DNA damage. DNA is repaired by a panoply of molecules such as endonucleases and ligases. Failure of this results in senescence, apoptosis or carcinogenesis. Mouse ESC have been shown to have an efficient defence against damage by insults such as by free radicals that decreases during differentiation (Saretzki et al., 2004). Mouse ESC cells are also efficient at p53-independent apoptosis (Aladjem et al., 1998) which avoids mutation in the cells. In human ESC many repair related genes are highly expressed (Miurra et al., 2004). In cells including mouse bone marrow stem cells a cyclin-dependent kinase inhibitor p16 ink4a appears to be involved in apoptosis caused by stress such that these stem cells accumulate more of the kinase inhibitor during ageing and are less able to survive stress (Janzen et al., 2006). Human ESC may provide a model for testing DNA damage by, for example, environmental insults and repair mechanisms.

\section{Pluripotency}

The ability of cells to express the correct proteins to maintain their role depends on transcription factors, epigenetics and micro-RNA.

\subsection{Transcription Factors}

One of the features of ESC is pluripotency, a feature that is lost during development and maturation. Certain transcription factors have been shown to be required for the maintenance of pluripotency in ESC including Oct 4 (Nichols et al., 1998); Nanog (Mitsui et al., 2003; Chambers et al., 2003) and Sox 2 (Botquin et al., 1998).

Recently somatic cells have been induced to behave in a way similar to ESC-Induced pluripotent stem cells (iPSC) appear to need the activation of only four genes to induce this state. In one paper these four genes are Oct 4, Sox-2, c-Myc and Klf-4 (Takahashi et al., 2007). Since then Thompson's laboratory found that Oct -4 , Sox-2, Nanog and Lin28 were needed to transduce their cells (Yu et al., 2007). How these genes are initially activated and maintained in ESC or iPSC may help elucidate mechanisms involved in development. How they are switched off during development may elucidate some mechanisms of ageing. However, the advent of iPSC challenges basic developmental biology and ageing, that somatic cells progress through a series of events and die, with only the germ cells being reset as pluripotential. iPSC allow the possibility of resetting adult somatic cells. What the gene expression profile 
will be, whether these cells express normal adult genes or reset their expression for example into embryonic forms of genes such as haemoglobin, has not been explored yet.

\subsection{Epigenetics of ESC}

Epigenetic mechanisms such as DNA methylation of cytosine in CpG islands (Bird and Wolff, 1999) post-translational modifications to histones (Jenuwein and Allis, 2001) and exchange of histones (Ahmad and Henikoff, 2002) may play a large role in gene expression by inhibition or activation of genes and hence in the developmental state of cells. Human ESC methylation patterns are just starting to be investigated.

Maitra et al. (2005) report methylation changes in three genes known to be altered in cancers. These changes were seen in late passage human ESC, suggesting that there are genetic changes during long-term culturing. In contrast, Rugg-Gunn et al. (2005) have investigated imprinting in six genes in human ESC without finding unusual methylation patterns over long passage numbers (between passage 40 and 155 ).

\subsection{Chromatin}

DNA is packaged around histone proteins in the nucleus. Histones can be modified by various mechanisms such as acetylation and methlylation to form transcriptionally open euchromatin where transcription factors can access and bind to promoter regions or closed, compact heterochromatin which are transcriptionally inactive. Initial work suggests that pluripotency in ESC may rely on unique histone modifications (Azuara et al., 2006; Bernstein et al., 2006) effecting the gene expression profile of ESC. Elucidating the mechanism of these changes may help understand the processes occurring during development, commitment, restriction of potentiality and ageing.

\subsection{Micro-RNA}

Micro-RNAs (mi-RNAs) are endogenous non-coding small RNA molecules which negatively regulate gene expression post-transcriptionally through mRNA cleavage, mRNA decay (Giraldez et al., 2006) or translational repression (see Carrington and Ambrose, 2003; Zahn et al., 2007 for review) and were first discovered by Lee et al. (1993). The expression profile of mi-RNAs differs in ESC from other tissue (Murchison et al., 2005). Studies have shown that mi-RNA regulate stem cell division so that stem cells can overcome the G1/S checkpoint by making stem cells insensitive to an environmental signals (Hatfield et al., 2005). Some mi-RNA are uniquely expressed in undifferentiated stem cells. There are around 6 (mi-RNA 290-295) with similar sequences found specifically in ESC, suggesting they may have a role in pluripotency (Houbaviy et al., 2003). These mi-RNAs may be involved in regulating the expression of transcription factors such as Oct 4, Sox 2 and Nanog or other regulators such as Notch. There is evidence in the iPSCs that a mi-RNA let7a inhibits one of the genes needed for induction, Lin 28 and it release from inhibition allows self-renewal and pluripotency (W. Lensch personal communication 2008).

\subsection{Somatic cell nuclear transfer}

Somatic Cell Nuclear Transfer (SCNT) has shown that donor nuclei can be re-programmed to develop into embryos regardless of the epigenetic state of the donor nucleus (Wilmut et al., 1997) such as seen in 'Dolly the Sheep'. However, this ability may be developmentally and species specific (Kuholzere-Cabot and Brem, 2002). The ability of older nuclei to be 'reprogrammed' by transfer into the cytoplasm of developmentally early cells implies that the cytoplasm may be the site of control of ESC. Micro-RNAs (mi-RNAs) are potential control factors in epigenesis and gene expression in ESC (Oakley and Van Zant, 2007). These may hold a key to the switching on of early transcription factors, chromatin remodelling and gene expression.

\section{Ethics}

As mentioned above, germ cells are the ultimate immortal cell and are of interest in terms of development and ageing. The isolation of unfertilised egg and sperm cells and their use for research is fraught with problems, as is the use of embryos (Cedar et al., 2006). Embryonic cells as mentioned are isolated from the ICM of a blastocyst that has been derived from IVF. The eggs and the sperm have been isolated and fertilisation of the eggs (up to about 30) is performed in vitro. Those eggs that are fertilised and form early blastocysts are used for assisted reproduction to be inserted into the uterus in the hope of a successful pregnancy. About $25 \%$ of IVF treatments will result in birth. Surplus embryos are frozen for future use. Couples having completed their families can then donate spare embryos or embryos that do not appear suitable for implantation, to research with consent. However, the process of isolating eggs is costly, not only in money, but also on the burden of time and medication to the female. The isolation of both eggs and sperm are intrusive and can be embarrassing. To expect, or exploit, others for research purposes requires very careful consideration. To use embryos to help the aged poses many ethical questions. This must be balanced by the fact that all medical interventions, from, for example, heart bypasses, insulin replacement therapy or hip replacement, are to prolong and improve life.

\section{Models of ageing}

Being able to carry out experiments to test how ageing occurs in humans is impeded due to lack of models. Models of human ageing are difficult due to the lack of material and the longevity of the species. Ageing is often a reflection of multiple divisions and environmental damage. From evidence so far, human ESC appear to have their genomes re-programmed into an early developmental state and maintain that state in the presence of the correct environment even through multiple divisions. Pluripotentiality and self-renewal are used as functional characteristics for ESC which are the basis of development and therefore, may define the youthful phenotype. ESC can provide a source of cells which can be used to model ageing. Factors such as genetic or environmental agents can be tested on these cell populations and changes in biomarkers of ageing measured. iPSC may also provide a source of cells to test the processes and mechanisms of ageing. These 'youthful' cells may, therefore enable us to have the key to the processes of ageing allowing us to investigate longevity, self-renewal and ageing mechanisms.

This paper proposes, therefore, that ESC and iPSC may offer a model of ageing such that the events of longevity can be separated from the processes and effects of ageing, allowing us to live long and prosper.

\section{Acknowledgements}

S.H.C was supported by an LSBU Researcher Grant.

\section{References}

Ahmad, K., Henikoff, S., 2002. Histone H3 variants specify modes of chromatin assembly. Proc. Natl. Acad. Sci. USA 99, 16477-16484.

Aladjem, M.I., Spike, B.T., Rodewald, W., Hope, T.J., Klemm, M., Jaenisch, R., Wahl, G.M., 1998. ES cells do not activate p53-dependent stress responses and 
undergo p53-independent apoptosis in response to DNA damage. Curr. Biol. 8 (3), 145-155.

Amit, M., Carpenter, M.K., Inokuma, M.S., Chiu, C.-P., Harris, C.P., Waknitz, M.A., Itskovitz-Elder, J., Thomson, J.A., 2000. Clonally derived human embryonic stem cell lines maintain pluripotency and proliferative potential for prolonged periods of culture. Dev. Biol. 227, 271-278.

Azuara, V., Perry, P., Sauer, S., Spivakov, M., Jorgensen, H.F., John, R.M., Gouti, M., Casanova, M., Warnes, G., Merkenschlager, M., Fisher, A.G., 2006. Chromatin signatures of pluripotent cell lines. Nat. Cell Biol. 8, 532-538.

Bernstein, B.E., Mikkelsen, T.S., Xie, X., Kamal, M., Heubert, D.J., Cuff, J., Fry, B., Meisener, A., Wernig, M., Plath, K., Jaenisch, R., Wagschal, A., Friel, R., Schreiber, S.L., Lander, E.S., 2006. A bivalent chromatin structure marks key development genes in embryonic stem cells. Cell 125, 315-326.

Bird, A.P., Wolff, A.P., 1999. Methylation-induced repression - belts, braces and chromatin. Cell 99, 451-454.

Bodner, A.G., Quellette, M., Frolkis, M., Holt, S.E., Chui, C.P., Morin, G.B., Harley, C.B., Shay, J.W., Lichtsteiner, S., Wright, W.E., 1998. Extension of life-span by introduction of telomerase into normal human cells. Science 279, 349-352.

Botquin, V., Hess, H., Fuhrmann, G., Anastassiadis, C., Gross, M.K., Vriend, G., Scholer H.R., 1998. New POU diner configuration mediates antagonistic control of osteopontin preimplantation enhancer Oct4 and Sox-2. Genes Dev. 12, 20732090.

Brandenberger, R., Khrebtukova, I., Thies, R.S., Miura, T., Jingli, C., Puir, R., Vasicek, T., Lebkowski, J., Rao, M., 2004. MPSS profiling of human embryonic stem cells. BMC Dev. Biol. 4, 10.

Carlson, M.E., Conboy, I.M., 2007. Loss of stem cell regenerative capacity within aged niches. Aging Cell 6, 371-382.

Carrington, J.C., Ambrose, V., 2003. Role of microRNAs in plant and animal development. Science 301 (5631), 336-338.

Carpenter, M.K., Rosler, E.S., Fisk, G.J., Brandenberger, R., Ares, X., Miura, T., Lucero, M., Rao, M.S., 2004. Properties of four human embryonic stem cell lines maintained in feeder-free culture system. Dev. Dyn. 229, 243-258.

Cedar, S.H., Cooke, J.A., Luo, Z., Patel, M.J., Minger, S.L., 2006. From embryos to embryonic stem cells: derivation and therapeutic potentials. Reprod. Biomed. 13 (5), 725-731.

Chambers, I., Colby, D., Robertson, M., Nichols, J., Lee, S., Tweedie, S., Smith, A., 2003. Functional expression cloning of Nanog, a pluripotency sustaining factor in embryonic cells. Cell 113, 643-655.

Giraldez, A.J., Mishima, Y., Ribel, J., Grocock, R.J., Van Dongen, S., Inoue, K., Enright, A.J., Schier, A.F., 2006. Zebrafish miR-430 promotes deadenylation and clearance of maternal mRNAs. Science 312 (5770), 75-79.

Hatfield, S.D., Shcherbata, H.R., Fischer, K.A., Nakahara, K., Carthew, R.W., RucholaBaker, H., 2005. Stem cell division is regulated by microRNA pathway. Nature 435 (7044), 974-978.

Houbaviy, H.B., Murray, M.F., Sharp, P.A., 2003. Embryonic stem cell-specific microRNAs. Dev. Cell 5 (2), 351-358.

Janzen, V., Forkert, R., Fleming, H.E., Saito, Y., Waring, M.T., Dombkowski, D.M., Cheng, T., DePinho, R.A., Sharpless, N.E., Scadden, D.T., 2006. Stem-cell ageing modified by the cyclin-dependent kinase inhibitor p16 ink4a. Nature 443, 421426.

Jenuwein, T., Allis, C.D., 2001. Translating the histone code. Science 293, 1074-1080

Kuholzere-Cabot, B., Brem, G., 2002. Aging of animals produced by somatic cell nuclear transfer. Exp. Gerontol. 37, 1315-1321.
Lee, R.S., Fairbaum, R.I., Ambros, V., 1993. The C. elegans heterochromatic gene lin-4 encodes small RNAs with antisense complementarity to lin-14. Cell 75 (5), $843-$ 854.

Li, X.-y., Jia, Q., Di, K.-q., Gao, S.-m., Wen, X.-h., Zhou, R.-y., Wei, W., Wang, L.-z., 2007. Passage number affect the pluripotency of mouse embryonic stem cells as judged by tetraploids embryo analysis. Cell Tissue Res. 372, 607-614.

Nichols, J., Zevnik, B., Anastassiadis, K., Niwa, H., Klewe-Nebenius, D., Chambers, I., Scholer, H., Smith, A., 1998. Formation of pluripotent stem cells in the mammalian embryo depends on POU transcription factor Oct4. Cell 95, 379-391.

Maitra, A., Arking, D.E., SHivapurkar, N., Ikeda, M., Stastny, V., Kassauei, K., Sui, G., Cutler, D.J., Liu, Y., Brimble, S.N., Noaksson, K., Hyllner, J., Schulz, T.C., Zeng, X., Freed, W.J., Crook, J., Abraham, S., Colman, A., Sartipy, P., Matsui, S., Carpenter, M., Gazdae, A.F., Rao, M., Chakravarti, A., 2005. Genomic alterations in cultured human embryonic stem cells. Nat. Genet. 37 (10), 1099-1103.

Mitsui, K., Tokuzawa, Y., Itob, H., Segawa, K., Murakami, M., Takahasi, K., Maruyama M., Maeda, M., Yamanaka, S., 2003. The homeoprotein nanog is required for maintenance of pluripotency in the mouse epiblast and ES cells. Cell 113 631-642.

Miurra, T., Luo, Y., Khrebtukova, I., Brandenberger, R., Zhou, D., Thise, R.S., Vasicek T., Young, H., Lebkowski, J., Carpenter, M.K., Rao, M.S., 2004. Monitoring early differentiation events in human embryonic stem cells by massively paralle sequencing and expressed sequence tag scan. Stem Cells Dev. 13, 694-715.

Morgan, D.O., 1995. Principles of CDK regulation. Nature 374, 131-134.

Murchison, E.P., PArtrideg, J.F., Tam, O.H., Chelouf,, S., Hannon, G.J., 2005 Characterisation of dicer-deficient murine embryonic stem cells. Proc. Natl Acad. Sci. USA 102 (34), 12135-12140.

Oakley, Van Zant, 2007. Unravelling the complex regulation of stem cells: implications for aging and cancer. Leukaemia 21, 612-621.

Rugg-Gunn, P.J., Ferguson Smith, A.C., Pedersen, R.A., 2005. Epigentic status of human embryonic stem cells. Nat. Genet. 37, 585-587.

Saretzki, G., Armstrong, L., Leake, A., Lako, M., von Zglinicki, T., 2004. Stress defense in murine embryonic stem cells is superior to that of various differentiated murine cells. Stem Cells 22, 982-991.

Steptoe, P.C., Edwards, R.G., 1978. Birth after the reimplantation of a human embryo. Lancet 2 (8085), 366

Takahashi, K., Tanabe, K., Ohnuki, M., Narita, M., Ichisaka, T., Tomoda, T., Yamanaka, S., 2007. Induction of pluripotent stem cells from adult human fibroblasts by defined factors. Cell 131, 861-872.

Thomson, J.A., Itskovitz-Elder, J., Shapiro, S.S., Waknitz, M.A., Swiergiel, J.J., Marshall, V.S., Jones, J.M., 1998. Embryonic stem cell lines derived from human blastocysts. Science 282, 1145-1147.

Weinberg, R.A., 1995. The retinoblastoma protein and cell cycle control. Cell 81, 323-330.

Wilmut, I., SChnieke, A.E., McWhir, J., Kind, A.J., Campbell, K.H.S., 1997. Viable offspring derived from fetal and adult mammalian cells. Nature 358, 810813.

Yu, J., Vodyanik, M.A., Smug-Otto, K., Antonosiewicz-Bourget, J., Frane, J.L., Tian, S. Nie, J., Jonsdottie, G.A., Ruotti, V., Stewart, R., Slukvin, I.I., Thomson, J.A., 2007. Induced pluripotent stem cell lines derived from human somatic cells. Science 318, 1917-1920.

Zahn, J., Doorman, P., Dorn, A., Dorn, D.C., 2007. Apoptosis of male germ-line stem cells after laser ablation of their niche. Stem Cell Res. 1, 75-85. 